\title{
Rural Landscape Preservation as a Core Rural Income Policy: The Case of the Longji Rice Terraces Area in Guangxi, China
}

\author{
Masumi Kikuchi
}

\begin{abstract}
In the Longii Rice Terraces Area, which is the focus of this paper, local residents receive from the government various types of eco-compensation that are aimed at preserving the vast terraced paddy landscape which has been a tourism resource. Local residents are dissatisfied with restrictions on their daily life imposed by strict government regulation, as well as with small amounts of compensation. Generally, attention is focused on this problem. However, is the situation of the area characterized by a strong government and weak local residents who are obedient to the government? One can consider that while government regulation exists, local residents increasingly tend to take advantage of government policy and strategically bring rural landscape preservation into play in order to increase their income.
\end{abstract}

Index Terms-Income policy, eco-compensation program, rural landscape, China.

\section{INTRODUCTION}

In today's China, which puts priority on economic growth, balancing economic growth and environmental preservation is always an important issue. This paper focuses on "eco-compensation" in China. The current eco-compensation program faces numerous issues concerning the rationality behind the amount of compensation, the compensation period, and the zoning of areas eligible for compensation. Consequently, in many areas, local residents are dissatisfied with the government and sometimes clash with it. The main issues involve forest preservation policies and the designation of national nature reserves, as reflected in projects for natural forest protection and forest restoration (from overcultivation). These policy measures are aimed at preventing destruction of the natural environment and land deterioration. Another policy tool is eco-compensation that promotes preservation of.

\section{ISSUES REGARDING ECO-COMPENSATION}

In China, eco-compensation is generally defined as adjustment of relevant actors' interests mainly through economic instruments for the purpose of environmental protection and utilization of ecosystem services [1]. Moreover, an eco-compensation program is defined as a public program that aims at preserving the ecological environment and promoting harmonious progress for man

Manuscript received November 7, 2014; revised January 19, 2015.

Masumi Kikuchi is with WASEDA University, Japan (e-mail: mjuchizhenchun56@gmail.com). and nature and adjusts the interests of stakeholders with a stake in government, the implementation of the market principle, and ecological protection that is based on capital for ecological protection, capital for potential progress, and the value of ecosystem services.

There are three main issues regarding the amount of compensation paid under the eco-compensation program, the period of compensation, and the criteria used for compensation. First, since uniform criteria are used, the amount of compensation received by residents of a region does not match the actual situation of the region. Since land productivity varies from one region to another, the amount of compensation exceeds the value of crop output per unit area in certain regions, whereas the amount falls short in other regions. In the latter case, dissatisfaction arises among local residents. Many scholars argue that it is irrational to apply uniform criteria to all regions in providing compensation [2]-[4].

Second, there is a negative effect of policies conducted according to China's Five-Year Plans. Compensation programs are often ended without the initial goals being realized: the end of a Plan period brings an end to these programs even if a certain level of environmental recovery is not achieved, or even if continued preservation is necessary.

Third, the problem of strained local government finances has been pointed out. LI considers the case of Guangdong Province where legislation related to compensation policy for public forests is most advanced [5]. He argues that although a local government's funds for protecting public forests are stipulated to be one percent of its total expenditure, it is difficult for local governments in the northern and eastern parts of Guangdong Province and the Xinlin district, which lack revenue, to come up with that one percent; he also argues that since districts with less revenue have larger public forests, their finances are strained as large forests require a large amount of spending. Local governments have a fundamental obligation to accomplish ecological restoration and provide compensation according to local residents' land ownership. However, there are cases in which the period of compensation is not extended, or compensation plans are terminated, because of such fiscal factors.

\section{EXAMPLES OF FAILURE IN ECO-COMPENSATION FOR LANDSCAPE PRESERVATION}

This paper considers the Longji Rice Terraces Area which is located in Guidongbei (northeast of Guilin) in Guangxi. Diverse ethnic minorities live in the area. This section discusses two cases where government policy failed. In both 
cases, the government tried to boost the local economy by providing eco-compensation for preserving a rural landscape that reflected a unique local culture; however, it failed in managing and utilizing resources and devastated a village.

Let us first consider the case of Huangyao-guzhen. The town is characterized by a typical karst landform with rock mountains that are similar to those in Guilin and Yangshou which are often depicted in Chinese-style landscape paintings. The townscape had a quality typical of traditional architecture with classic Chinese gardens. Surrounded by a rural landscape, the entire town had a consistent look with black stone pavements and black tiled roofs. As the landscape became a tourism resource, the government tried to promote the local tourism industry. In order to attract tourists to Huangyao-guzhen, in 1985 the government implemented a policy that forced all local residents to move outside of the village in return for eco-compensation. However, without occupants, houses all over the village crumbled in one or two years.

In another example, in 1991 the government provided eco-compensation to promote tourism in Baimianyaozhai. As a result of the government's attempt at regional development through tourism, the relationship between local residents and the government and government-controlled travel agencies deteriorated due to conflicting interests. Local residents then tried to stop relevant actions by the government and the travel agencies and to manage tourism businesses by themselves, but to no avail. They rejected government support and control and started to manage and administer tourism activities, but their operation did not function well due to insufficient funds and a lack of management skills. Clashes among local residents occurred as a result. Consequently, the local tourism industry declined continuously; many of the local residents left the village and started to work elsewhere; local agricultural activity, which had been vigorous before the advent of tourism, went downhill. What we see today is a depopulated village.

Guangxi, an ethnic minority autonomous region, has ethnic cultures and types of natural environments that cannot be seen in other regions in China, and these factors merge to form the region's rural landscape. Today, the landscape itself, which comprises all elements in the region, is regarded as a tourism resource. However, Guangxi has a large number of poverty-stricken areas compared to other regions, and attempts have been made to move away from a self-sufficient lifestyle and to promote rapid economic development through tourism. In more than a handful of cases, these efforts have led to failed resource allocation in local communities, deterioration of commons, and total collapse of villages.

\section{THE RURAL LANDSCAPE OF THE LONGJI RICE TERRACES} AREA

The Longji Rice Terraces Area is in Hepingxiang, Longsheng (a county of Guangxi) which is approximately 70 $\mathrm{km}$ from central Guilin. The area includes three villages: Ping-an Village, Dazhai Village, and Guzhuang Village. The size of the scenic area that attracts tourists is $66 \mathrm{~km}^{2}$; the size of the area that is accessible for sightseeing is $20 \mathrm{~km}^{2}$. The highest and lowest points in the area are $1,850 \mathrm{~m}$ and $300 \mathrm{~m}$ above sea level, respectively. Terraced paddy fields are most likely to be found on mountainsides ( 26 to 30 degrees in slope) between 300 to $1,100 \mathrm{~m}$ above sea level. As for the climate, the area has a subtropical monsoon climate and is affected by seasonal winds - southeast winds in summer and northwest winds in winter. The annual average temperature is 14.4 to 16.9 degrees Celsius; the annual precipitation is 1,600 to $1,733 \mathrm{~mm}$; the annual average hours of sunshine is $1,225.7$ hours [6]. Fig. 1 shows terraced paddy fields resembling the back of a dragon, the origin of the name Longji.

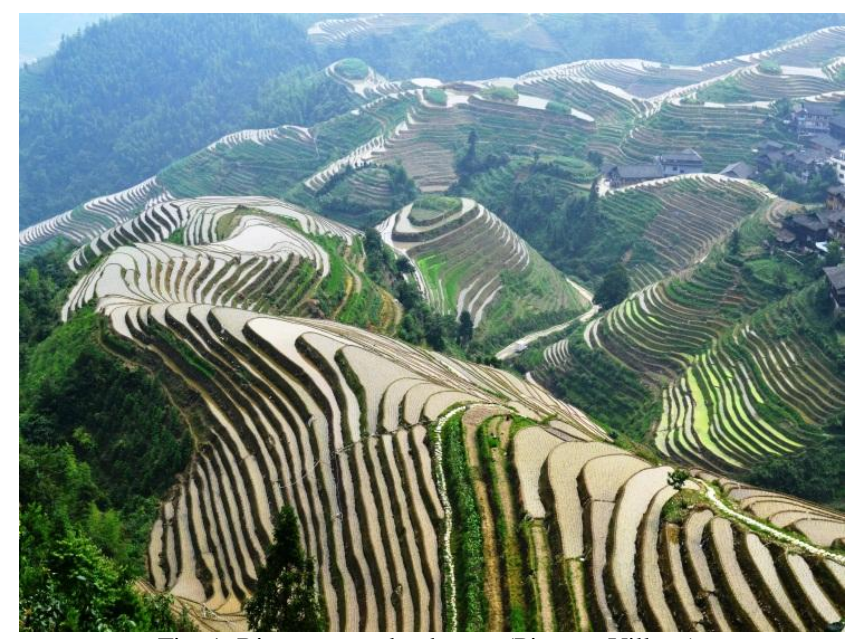

Fig. 1. Rice terraces landscape (Ping-an Village).

Development for tourism in the Longji Rice Terraces Area began in 1990. As tourists visited the area, the head of Ping-an Village adopted an entrance ticket system in 1994. This was the beginning of the entrance ticket system in Longji. Subsequently, in 1997 the local (township-level) government and the travel agencies controlled by it provisionally started to manage entrance tickets, which tourists needed in order to enter the area. In 1999, tickets began to be officially managed by the government (Longsheng Government Tourism Bureau) and travel agencies (Longsheng General Tourism Corporation and Guilin Tourism Development Corporation Limited). The revenue from the tickets is used to maintain or build stone pedestrian streets, fences for the safety of tourists enjoying the view of terraced paddy fields, and restrooms in the villages. Seven percent of the revenue is distributed among villagers as funds for promoting the maintenance of the paddy fields. However, they argue that seven percent is too low and have had negotiations with the government.

In 2003 the Longsheng government introduced a new policy for tourism development based on the concepts of government leadership, market operation, corporate management, and public participation. More specifically, the policy promotes development of tourism resources through management of the tourism industry according to the following factors: market forces; zoning in the scenic area; infrastructure development; advertisement to the outside world; clarification of development rights and management rights at the time of a general liberalization of the tourism industry; securing of funds necessary for tourism development in the county; adherence to advanced management ideas; and formation of the tourism industry based on diversified investment. According to Guangxi Rural Area Development Research, the ultimate goal of these 
actions is to gradually develop the villages, where subsistence farming was once prevalent, and show a model of how a poverty-stricken area can move out of poverty through tourism development [7]. In China, the farming villages in Guangxi that are considered in this paper are recognized as poverty-stricken areas whose economic level is particularly low. In this context, government subsidies provided to the Longji Rice Terraces Area and efforts to improve people's daily life through infrastructure development began with the start and promotion of tourism in recent years. The government regards these measures as part of its policy to increase local residents' income.

\section{REGULATION AND ECO-COMPENSATION FOR RURAL LANDSCAPE PRESERVATION}

\section{A. Regulation to Protect Scenery and Residents' Dissatisfaction}

In 2005 the Longsheng government set up a county-level office for scenic area management in Ping-an Village. Subsequently, Ping-an Village and Dazhai Village started to take into consideration the landscape of terraced paddy fields and consistency with traditional houses; designated places in each village as no-new-construction zones in 2006; and have managed the scenery since then. There is no compensation provided for this regulation [8].

Local residents cannot build structures in places that are designated by the government as no-construction zones for the purpose of landscape preservation, even though they have the ownership of the land or the right to use the land. For example, in an interview, a 25-year woman in Dazhai Village answered that when her brother built a house in 2006 it was demolished by the government because the site was in a no-construction zone; that he lost more than 100,000 yuan; that the sole reason for the demolition was that the house was destroying the surrounding scenery; and that the relevant regulation began in 2006. Also, in Ping-an Village, in 1998 the government demolished a bridge built by the village for the same reason, and there have been more than ten cases where houses being built by farmers were demolished. Since not only house construction and consistent exterior appearance, but also the setting up of a shed for storing agricultural tools and the planting of trees around a house are subject to such regulations, more than a few residents are dissatisfied with the strict government regulation.

As for eco-compensation that is not related to the regulation to protect scenery, compensation is provided for the obligation imposed by the forest restoration policy that terraced paddy fields in areas near water-source-protecting forests be turned back into forests. However, the amount of rice harvested from terraced paddy fields near water-source-protecting forests at mountaintops is small to being with, the amount of compensation provided based on uniform criteria does not go below the profit from crop production. Therefore, residents are not dissatisfied with the compensation.

\section{B. Eco-compensation through the Rapeseed Flowers Project}

Control over the appearance of houses and the creation of scenery based on traditional farming on terraced paddy fields are the most basic targets of government regulation. Today, there are many other measures for landscape preservation and scenery creation, and the government provides relevant instructions and eco-compensation. Fig. 2 shows a public notice informing of a program under which local residents can receive a subsidy by cultivating and maintaining farmlands and mountains according to the government's rural landscape development plan. The central part of the program is the subsidy provided through the Rapeseed flowers Project.

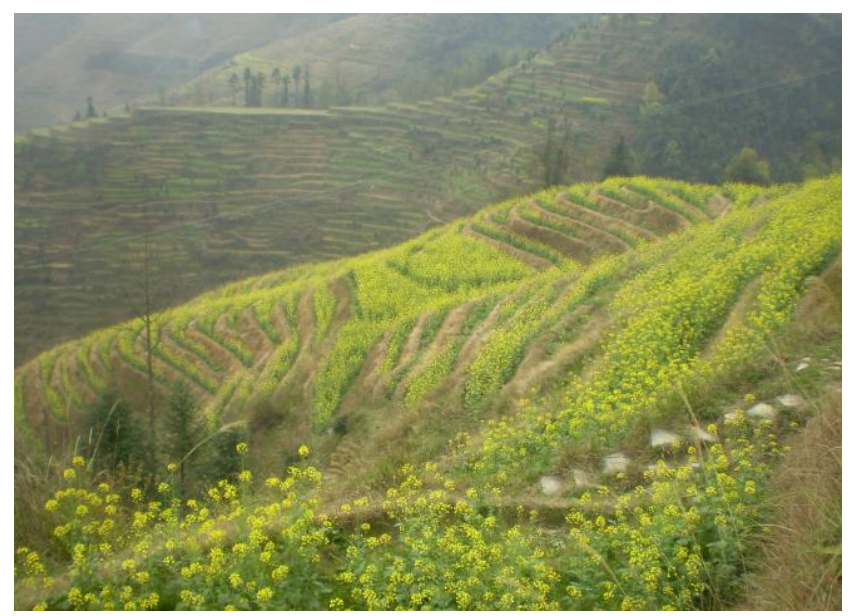

Fig. 2. Rapeseed flowers in rice terraces (Dazhai Village).

Scenery creation during the farming off-season through projects like the Rapeseed flowers Project is conducted, not for farming purposes, but for tourism. A survey reveals that local residents do not utilize rapeseed plants for oil or food, but simply grow them for the sake of scenery creation, and that a handful of residents use rapeseed plants as pig feed after their flowers wither and die. The survey also reveals that the owners of terraced paddy fields in government-designated zones where rapeseed plants can be grown during the farming off-season are forced to participate in the project, except for the cases in which paddy fields are in areas at relatively high altitudes or areas where tourists rarely visit.

According to Mr. Pan, the head of the Dazhai village committee, for one or two years after the start of the Rapeseed flowers Project many local residents complained about the additional off-season work that must be performed due to the project. The committee head also stated that the tourists appreciated the rapeseed field landscape very much; that local residents gained the habit of showing the beautiful scenery of terraced paddy fields to tourists throughout a year, even during the farming off-season; and that the project eventually made local residents think that preserving the paddy field landscape was the most important factor in the growth of tourism.

In 2009, the project experimented with different types of rapeseed plants according to the local climate and soil, and the amount of the subsidy was 100 yuan per mu $(1 \mathrm{mu}$ is approximately 6.667a). Subsequently, in 2011, rapeseed plants were grown in fields in the three villages of the Longji Rice Terraces Area, including Dazhai Village, and the total area of the fields was 1,080 $\mathrm{mu}$. In 2012, the project gained official support as the bill concerning the growing of rapeseed plants in the Longji scenic area was passed in the Longsheng Autonomous County legislature. As a result, 
official rules specifying the areas for growing the plants, the kinds of plants used, and the period of planting were implemented and brought an end to the experimental growing of the plants. Also, steady payments of eco-compensation (130 yuan per $m u$ ) began.

\section{Winning Eco-compensation by Persuading the Government}

Today, infrastructure development in the Longji Rice Terraces Area has been completed, enabling people to use roads and electricity and gas services. The subsidy program in the area thus focuses mainly on local scenery creation.

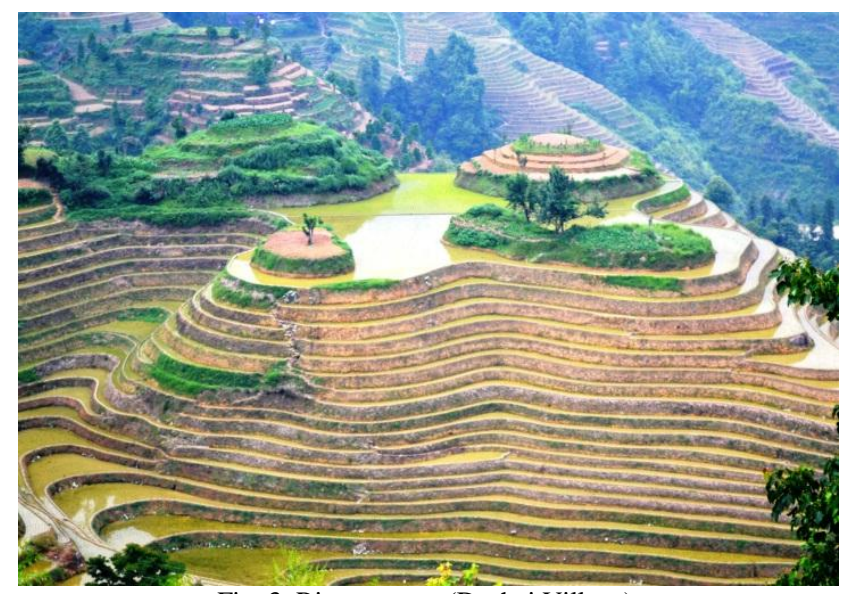

Fig. 3. Rice terraces (Dazhai Village).

Fig. 3 shows an example of landscape development in Dazhai Village: in 2010 the single-level paddy field located at the top was replaced with trees and plants and was made into a miniature garden. Terraced paddy fields after landscape development, trees and plants were planted in the top paddy field.

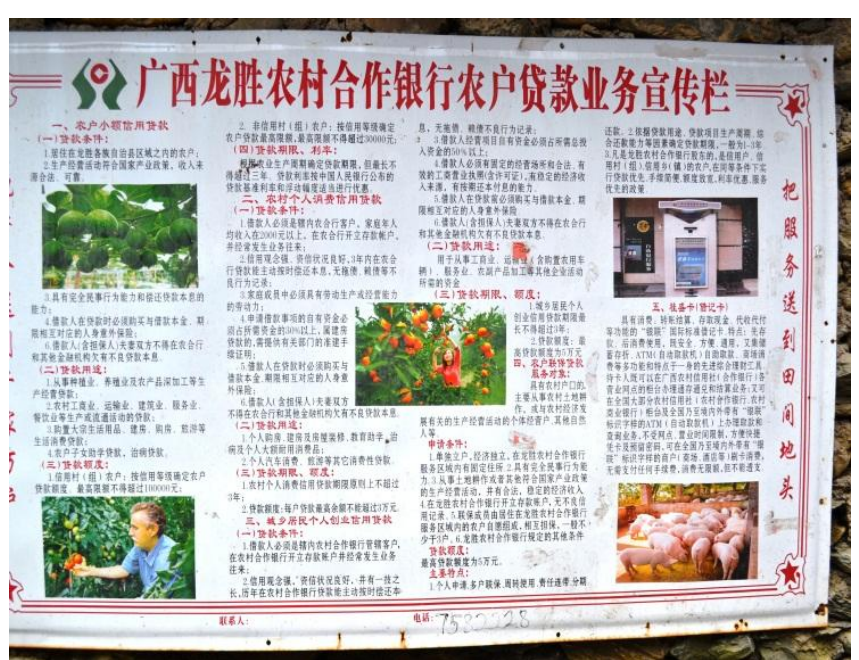

Fig. 4. Rural Micro-credit program. (Dazhai Village).

The development was a result of the village committee playing a central role in gaining cooperation from the household that was farming in the paddy field. The three villages in the Longji Rice Terraces Area actively invited a delegation from the government, and the local residents showed to the government concrete examples of landscape development, like the one described above, as well as relevant creative measures and asserted to the government that the villages are exemplars of villages whose development is driven by voluntary efforts of the villagers as in the government's idea for creating new socialist farming villages. As a result, in 2011 the Longji Rice Terraces Area was certified as an exemplary place for farm tourism in China and was designated as a national-level AAAA scenic area for tourism. Also, Dazhai Village was honored for its original Chinese village landscape, which brought a separate subsidy to the residents. In addition, the village committees requested the government to introduce a micro-credit program which they learned in a government-sponsored field trip to other villages. In 2010, a micro-program program was introduced with a goal to balance tourism and agriculture, and many local residents have utilized the program.

Fig. 4 shows the system of Rural Micro-credit program of Agricultural Cooperative Bank of China.

\section{RESPONSES TO ISSUES INVOLVING TRADITIONAL ECO-COMPENSATION}

As discussed in Sections I and II, the issues involving eco-compensation in China are mainly related to the criteria used for compensation, the amount of compensation, and the compensation period, and many failures have been pointed out with regard to eco-compensation aimed at regional development based on the preservation and utilization of the local rural landscape as a tourism resource. In connection with these issues, the eco-compensation for rural landscape preservation in the Longji Rice Terraces Area can be considered as follows. The criteria used for the eco-compensation raised questions about their rationality and caused dissatisfaction among local residents. For example, the Rapeseeds Project for the farming off-season provided a subsidy of 100 yuan per $m u$ in 2009 and 130 yuan per $m u$ starting in 2012. Also, the proportion of revenue from the entrance tickets (which tourists need in order to enter the area) that is distributed to the villages is set to seven percent. However, there is no scientific rationale behind these numbers, and the government provides compensation based on criteria set according to its fiscal resources. With regard to the compensation period, similarly to the cases of other areas, it is set to five or eight years for the Longji Rice Terraces Area. But, due to requests from the local residents and decisions made by the government, the compensation periods have been renewed or extended. Local governments' strained finances are closely tied to their inability to extend the period of compensation. However, in the case of the Longji Rice Terraces Area, the government is fiscally sound as the proceeds from tourism have increased year after year. Particularly, since many of the travel agencies offering services related to the Longji Rice Terraces Area are government-controlled travel agencies, government finances, which are critical for the compensation program, have not faced serious problems.

As mentioned earlier, it is true that there are local residents who are dissatisfied with the obligation to participate in landscape preservation activities that is unilaterally imposed by the government. The case of Longji, however, is not characterized by a strong government and weak local residents being exploited by it. As a Chinese saying goes, "the government has policies; the people have responses." The local residents have regarded farming in terraced paddy 
fields, which used to be conducted mainly for food production, as farming that contributes to scenery creation and landscape preservation and understand well that their efforts are rewarded in the form of eco-compensation. They then strategically engage in scenery creation and landscape preservation with voluntary actions that are consistent with the government's policies and ideas.

\section{CONCLUSION}

Today, people in areas like the Longji Rice Terraces Area recognize that their rural landscape is the most important resource, and government subsidy policies reflect this recognition. In such areas, a rural landscape that is highly appreciated by outsiders has become the central concern in the government's income policy for the areas. Also, in these areas, there is a concern about future continuation of farming in terraced paddy fields because of an increasing number of people working in the tourism industry and an increasing number of land plots where farming is abandoned as a result of selective breeding of rice plants and a declining labor force attributed to population aging. In areas with a rural landscape that is appreciated by people in China and foreigners, if its future maintenance becomes difficult, it is considered important that the government provide support through policies and direct subsidies. This is because the rural landscape in these areas is regarded as a public good whose value is recognized both in China and internationally. Based on the discussions in this paper, it can be concluded that the residents of the Longji Rice Terraces Area have taken advantage of changes of times and changes in demands from society; have built a better relationship with the government compared to many other rural areas; and are aiming for further regional growth.

\section{REFERENCES}

[1] W. H. Ye and B. Wei, Measurement and Application of Urban Ecological Compensation, China Environmental Science Press, Beijing, China, pp. 298-301, 1998.

[2] F. B. Kong, Chinese Ecological Compensation Mechanism, Utilisation and Policy Design, China Environmental Science Press, Beijing, China, 2010, p. 66.

[3] S. D. Li, Research on Conversation of Farmland to Forests in China, Science Press, Beijing, China, 2004, pp. 7-8.

[4] S. F. Li, New Century in China: Economic Analysis of fTuigen-Huanglin, Huangcao Policy, China Agriculture Press, Beijing, China, pp. 107-114, 2009.

[5] M. Y. Li and A. Zheng, "Ecological benefit compensation policy and regulation for public welfare forest," Journal of Nanjing Forestry University(Humanities and Social Sciences Edition), vol. 3, no. 2, Nanjing, China, 2003.

[6] G. W. Cheng, D. Q. Wang, L. G. Qin, Y. F. Kong, Q. K. Yan, and G. H. Qin, "Tourism development and ecological conservation in Longji, Guangxi, China," Journal of Guilin University of Technology, Guilin University of Technology, vol. 22, no. 1, Guangxi, China, p. 94, 2002.

[7] Guangxi Rural Area Development Research, Building a New Socialist Countryside in Depressed Area in China, UESTCP, Chengdu, China, 2007, p. 32.

[8] M. Kikuchi, Dynamic Conservation of the Rural Landscape as a New Resource: A Case Study of the Longji Rice Terraces in Guangxi, China, Waseda University Publish, Tokyo, Japan, 2012, p. 125.

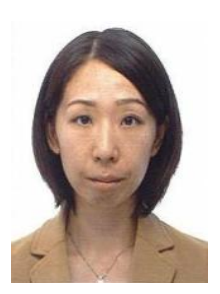

Masumi Kikuchi is a Japanese. She is a research associate with School of International Liberal Studies, Tokyo, Japan, Faculty of International Research and Education, Waseda University. She has got the Ph.D. degree in international studies from Waseda University. From 2005 to 2006, she was an assistant professor in School of International, Guangdong Peizheng College, Guangzhou, Guangdong, China; from 2006 to 2008, she was an assistant professor in School of International, Qingdao Technological University, Qingdao, Shandong, China. 